\title{
Are finance, management, and marketing autonomous fields of scientific research? An analysis based on journal citations
}

\author{
Pedro Cosme Vieira $\cdot$ Aurora A. C. Teixeira
}

Received: 15 August 2007/Published online: 18 September 2010

(C) Akadémiai Kiadó, Budapest, Hungary 2010

\begin{abstract}
Although there is considerable consensus that Finance, Management and Marketing are 'science', some debate remains with regard to whether these three areas comprise autonomous, organized and settled scientific fields of research. In this paper we aim to explore this issue by analyzing the occurrence of citations in the top-ranked journals in the areas of Finance, Management, and Marketing. We put forward a modified version of the model of science as a network, proposed by Klamer and Van Dalen ( $\mathrm{J}$ Econ Methodol 9(2):289-315, 2002), and conclude that Finance is a 'Relatively autonomous, organized and settled field of research', whereas Management and (to a larger extent) Marketing are relatively non-autonomous and hybrid fields of research'. Complementary analysis based on sub-discipline rankings using the recursive methodology of Liebowitz and Palmer (J Econ Lit 22:77-88, 1984) confirms the results. In conclusions we briefly discuss the pertinence of Whitley's (The intellectual and social organization of the sciences, 1984) theory for explaining cultural differences across these sub-disciplines based on its dimensions of scholarly practices, 'mutual dependency' and 'task uncertainty'.
\end{abstract}

Keywords Citations · Finance $\cdot$ Management $\cdot$ Marketing $\cdot$ Autonomy

JEL Classification C89 A A12

P. C. Vieira

Faculdade Economia, Universidade do Porto, Rua dr Roberto Frias, 4200-464 Porto, Portugal

A. A. C. Teixeira (ه)

CEF.UP, Faculdade Economia do Porto, Universidade do Porto, Rua Dr Roberto Frias,

42200-464 Porto, Portugal

e-mail: ateixeira@fep.up.pt

A. A. C. Teixeira

INESC Porto, Porto, Portugal

A. A. C. Teixeira

OBEGEF, Faculdade de Economia do Porto, Universidade do Porto, Porto, Portugal 


\section{Introduction}

Citing patterns are produced by a collective of authors publishing in a certain source (e.g., journals) in a given year. These patterns reveal how this community perceives its relevant environments at the time (Borgman and Furner 2002), but in the extent that citations refer to journal articles, they would only reflect a part of the intellectual structure of the field (van Raan 2004).

Citation behaviour is heavily dependent on the 'field' of research (Wouters 1999; Moed 2005) and may reflect both cognitive and social networks and relations (Braam et al. 1991). As Wouters (1999) correctly states, the (social) sciences host many types of citing cultures, with every 'specialty' and 'discipline' speaking its own language (de Wilde 1992).

'Fields' may be defined at various levels, from small research fronts to broad academic disciplines (Zitt 2006). Indeed, many definitions of scientific areas and disciplines can be put forth but, as Zitt (2006) incisively puts it, "natural borders are an illusion".

Conducting citation studies at the disciplinary level overlooks a considerable degree of heterogeneity underlying every subject. For instance, although Rigney and Barnes (1980) found that economics was much less likely to cite documents outside the discipline than other social sciences such as psychology and sociology, reinforcing their conception of economics as a comparatively insular scholarly enterprise, Waller (2006) showed that within the 'discipline' of economics, the subfields 'economic theory', 'financial economics', and 'development economics' reveal widely-diverging patterns of citations. ${ }^{1}$ Exploring also variations in the format of cited materials by sub-discipline, Clements and Wang (2003) noted that researchers in the area of finance were much more likely than the average economist to cite journal articles, due to the rapid pace at which this subfield is evolving.

There is a massive amount of literature on bibliometric methodologies aimed at identifying cognitive or social structures in scholarly research activities (van Raan 2004; Moed 2005), including those based on an analysis of cited references, cognitive terms in titles, abstracts, and keyword listings of individual articles. Such methodologies provide tailormade delimitations of scholarly and technological fields, often on a paper-by-paper basis, based on co-citation analysis (Small 1977; Small and Sweeney 1985; Schwechheimer and Winterhager 2001), co-word analysis (Callon et al. 1983; Bhattacharya and Basu 1998; Noyons et al. 1999; Lewison 1999), combined co-citation and co-word analysis (Braam et al. 1991), and author co-citation analysis (White and McCain 1998). More recently, domain visualization has emerged as a powerful tool for representing the internal structure of a field (Garfield 1986; Noyens and van Raan 1998; Börner et al. 2003; Borgman 2007). According to Garfield (1986) "drawings... and maps [scientography] appear prominently in the scientific literature because they do what words or numbers fail to do (or do more concisely and clearly what words and numbers do)".

This delineation of science in terms of specialties and disciplines has represented quite tough long-standing disputes among some of the most well-known researchers (Leydesdorff 2002, 2004a, b, 2008; Leydesdorff and Cozzens 1993; Leydesdorff and Zhou 2007), with some admitting that no single 'best' classification is possible (Bensman 2001; Leydesdorff and Bensman 2006) and that "[to find a robust way of delineating

\footnotetext{
1 Waller's study however, suffers from methodological problems which pertain to the fact that it assigns subject categories ('economic theory', 'financial economics', and 'development economics') only to one given journal (respectively, Journal of Economic Theory, Journal of Financial Economics, and World Development).
} 
science] is not a viable project". Leydesdorff (2007) further elaborates on that impossibility by attributing it to the fuzziness of (journal) sets: scientific journals tend to cite one another in dense clusters which represent specialties, but some journals cite and are cited across different fields (Narin et al. 1972). This, according to Leydesdorff (2007), hampers a bottom-up aggregation as the decomposition remains sensitive to the choices of the various parameters involved, namely the seed journal(s) for collecting a citation environment, the threshold levels, similarity criteria, and the clustering algorithm.

Recognizing that the aggregation is never robust, Leydesdorff (2007) suggests that the choice on the method of aggregation might be best left to the user. He further adds that "ideally, a system should allow users to select one or more journals ... and then generate the relevant environments ... dynamically".

Although Leydesdorff's suggestions were made in the context of mapping visualization, they are quite pertinent to our research aim. Our key research question is whether Finance, Management and Marketing comprise 'autonomous' scientific fields of research. We explore this issue by analyzing the occurrence of citations in the top-ranked journals in the above-mentioned fields, departing from the 'delineation' associated with ISI subject categories or 'specialties'. As such, we consider that the relative importance of journals, more specifically, the characteristics and relative patterns of citation, are a valuable tool to assess the degree of autonomy/dependence of particular fields of research, namely some less explored 'specialties'-Finance, Management, and Marketing-from a scientometrics view point.

Undeniably, little research exploring the relations between journals or academic business/management (sub)disciplines has been undertaken (Biehl et al. 2006). Most of the scientometric studies involving mapping and delineation of 'fields' focus mainly on 'sciences' (e.g., Biomedical—Lewison 1999; Physics-Bhattacharya and Basu 1998; Neuroscience-Schwechheimer and Winterhager 2001; Nanoscience and nanotechnologyLeydesdorff 2008), less on social sciences (e.g., Sociology—Swygart-Hobaugh 2004), and, to the best of our knowledge, none on Finance, Management or Marketing. Some (rather few) scientometric studies on these latter fields exist but they focused on topics which do not explicitly deal with the field's delineation: quality of collaborative research in Finance (Avkiran 1997), authorship and citation patterns in Management Science Journal (Eto 2002), efficiency procedures in publication in Management science (Lozano and Salmerón 2005), and scholars' influence on Marketing (Saad 2010).

Standing on the shoulders of giants, namely the "Father of Scientometrics", Derek de Solla Price (Garfield 2009), who in his 1965's work first shed light on the network or graph properties of citation behaviour (Newman et al. 2006), in the present paper we operationalize the theoretical considerations of Klamer and Van Dalen (2002) involving a network typology of information exchange in science. Specifically, we propose first a (theoretically) modified version of science as network clusters (Klamer and Van Dalen 2002) in order to understand the cognitive structures, in particular, the degree of autonomy and scientific organization of sub-fields based on journal citations. Then, we put forward a hybrid method, which combines the ISI classification of journals and citations. This groupjournal ranking involves a three-step procedure which starts with a list of ISI top-cited journals in Finance, Management and Marketing, then a classification and ranking of these journals into groups, by observing who cites whom, and finally, based on the citation data, the computation of sub-discipline rankings using the recursive methodology of Liebowitz and Palmer (1984) which, relying extensively on Moore's (1972) seminal work, computes the average relative impact of each paper published. 
Although with similar goals, methodologically our proposal is distinct from recent attempts to use measures such as centrality and betweenness to characterize both the status of a field and the status of a journal within it (e.g., Leydesdorff 2007). In contrast with these latter approaches, which are based on Social Network Analysis (SNA) techniques, our proposal is based on a recursive algorithm (cf., Liebowitz and Palmer 1984) resulting that the final delineation of the field does not depend on the choice of the seed journal. Moreover, they do not look into direct citations links but compare the citation profiles of all journals in the set of citing journals (knowledge base) and being cited journals (citation impact), taking the argument that the similarity in citing behavior and in being perceived contains more stable, structural information about journals belong to the same class or field than if one looks at direct citations (Leydesdorff 2007). ${ }^{2}$

The paper is structured as follows. The next section presents some considerations on journal rankings, paper citations and the autonomy of scientific fields of research. Then, in Sect. 3, the methodology used and the results of our research are explained. Finally, the main points of the study are listed in the Conclusions.

\section{Citations in top-ranking journals and the autonomy of scientific fields of research}

Research is disseminated in many varied forms, through books, journals, conference presentations, word-of-mouth or the Internet, among others (Moed 2005; Borgman 2007). Due to its regularity, mainstream academic journals provide good possibilities, or a valid context, for a reliable measure of quality. It can be argued that publishing a book can enhance an academic's reputation. However, the heterogeneous nature of books and publishers makes it extremely difficult to derive an objective quality measure. Therefore, virtually all studies since the 1980s have ranked economics departments on the basis of refereed journal articles (Macri and Sinha 2006). ${ }^{3}$

Additionally, citations are often found to be the best quantifiable measure of journal quality and importance (Alexander and Mabry 1994) and are frequently used to establish an accurate ranking of journals (Bush et al. 1974; Gerrity and Mckenzie 1978; Hamelman and Mazze 1974; Liehowitz and Palmer 1984; Mabry and Sharplin 1985; Schwert 1993; Macri and Sinha 2006). Rankings of journals (both in economics and finance) rely primarily on one of two different methods: opinion surveys or the frequency of journal citations in research. However, perceptions gleaned from surveys are much less tangible and may be easily influenced by the design of survey instruments. One potential problem is that the survey may fail to include relevant journals that have significant bearing on the discipline. The citations approach, which involves analyzing the frequency of journal citations found in published research, is a more objective technique for determining journal quality as most scholars perceive it - the contribution of information and ideas to current published research (Parks 2002). Since articles in leading journals certifies one's membership in the scientific elite, not only does the impact factor of journals matter, but also the

\footnotetext{
${ }^{2}$ We sincerely acknowledge one of the referees for highlighting this important point. Accordingly, one interesting path for future research would be to compare Leydesdorff's approach with ours over a longer period in time.

${ }^{3}$ It is important to refer that some books and conference proceedings go through scientific peer review and that even for journal articles the peer review process is not always as objective as one would expected (García-Aracil et al. 2006), questioning in part the 'reliability' of academic journals as unique portraits of 'quality'.
} 
total number of publications is of great importance since frequent publications sustain one's career, and are well-seen when applying for funds (Fronczak et al. 2006).

As Alexander and Mabry (1994) argue, knowing the relative importance of journals is valuable in many ways: as input in personnel decisions involving selection, compensation, promotion, and tenure; as information for authors who must decide which journals are the best sources of useful, relevant literature and which are the best (most influential) outlets for their research results; as information for individuals, departments, and libraries that must allocate scarce resources to reading and/or buying journals; and as data for editors of journals to use in assessing their own performance and making the necessary adjustments to achieve their goals. We add further, in the line of Waller (2006), Biehl et al. (2006) and Leydesdorff (2007), that the relative importance of journals in a given area, more specifically, the characteristics and relative patterns of citation, may be a valuable tool to assess the degree of autonomy/dependence of that particular field of research.

As Fry (2004) correctly underlines, knowledge is not a homogenous whole, but a patchwork of heterogeneous fields. These fields are most visible as embodied in academic disciplines, which have distinct cultural identities shaped by intellectual and social considerations. Additionally, an effective understanding of the similarity and difference in patterns of scholarly communication needs to take the fine-grain of specialist fields as the unit of analysis, rather than the course-grain of the discipline. Indeed, academic disciplines have distinct cultural identities, which are shaped by the social, 'establishment of reputation', and the epistemological, 'promotion of knowledge', elements of scholarly activity (Becher 1989).

According to some authors (e.g., Parks 2002; Klamer and Van Dalen 2002), academic publishing is apparently 'gripped' in a path-dependent equilibrium with scientists converging in clusters of concurring scientists. Klamer and Van Dalen (2002, p. 294) note that "The super star SSCI [Social Science Citation Index] journal has an impact factor of 11.3, which means that the average article in this journal receives 11.3 citations (including selfcitations) in the first 2 years following the publication date. In contrast, for $80 \%$ of all journals, influence on the scientific community is small if not negligible-the median impact factor for the social sciences journals is 0.5 (which includes self-citations of authors) whereas the top-10\% journal has an impact factor of 1.65."

In van Raan's (2000) view, modern science displays a 'fractal-like structure', that is, each research cluster generates its own publications and forms a mutual citation society and, as time goes by, this cluster generates a more refined cluster, which again generates 'offspring'. Following this line of reasoning, one would expect that those who write, for instance, in the Journal of Finance cite other articles in the same journal (journal selfcitation rates are generally high). Thus, even if these articles are not cited elsewhere, their citations add to the total (provided they are included in the SSCI). Klamer and van Dalen (2002) argue that the 'inflation of citations' observed in recent years (Macri and Sinha 2006) indicates a rapid expansion in the number of clusters in the world of the sciences. These authors put forward a set of descriptive models of citation flows among journals, a typology of network structures, designed for understanding 'science': (a) Lone wolves (no interaction); (b) The Science Ideal (full interaction); (c) Technology leader sets the standard (of language, methods, issues); (d) Learning from neighbours; (e) Minimal network structure with a core (Fig. 1).

The Lone Wolves model (a) reflects the extreme (and non-realistic) consideration that isolated individuals can make contributions to science, not having the need to interact with each other. In sharp contrast, we have the fully integrated scientific community (b), "the ideal picture of science, a spontaneous order" (Klamer and van Dalen 2002, pp. 306-307), which nevertheless stands as non-realistic as the former and does not offer much to the 


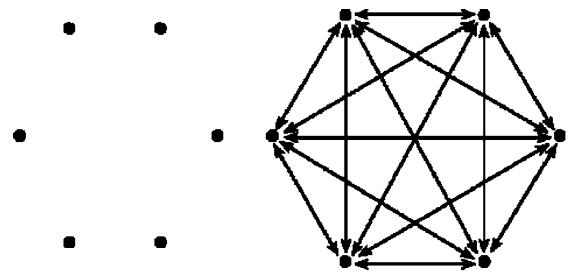

(a)

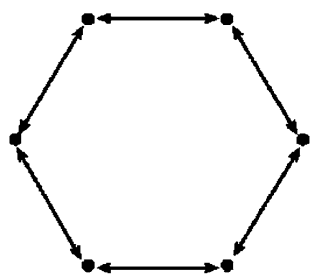

(d)

(b)

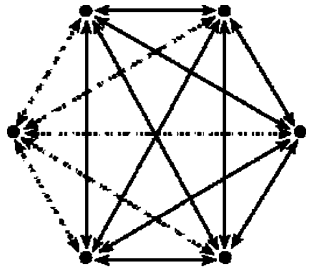

(c)

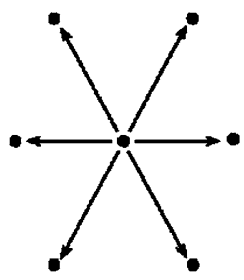

(e)

Fig. 1 Network interaction structures Source: Klamer and Van Dalen (2002, p. 306) Note: Network models (b) and (c) differ in that in (b) the line style is always straight, whereas in (c) some of the links between nodes are represented by a dashed line, reflecting weaker links or interactions between nodes

understanding of science since it lacks plausibility; in short, it considers science as a neoclassical 'market of supply and demand', where the world of science is fully integrated, not a solitary affair, but an activity conducted in overlapping neighbourhoods (Polanyi 1962), in which everyone has an equal chance of meeting each and every participant (Franck 1999).

The model (c) in which a leader sets the standard adds some plausibility to modelling the world of scientific publication. It is worth remembering, as Frey and Eichenberger (1997) note, how US universities and journals set standards for the rest of the economic community.

According to Klamer and van Dalen (2002), the star model (e) presents the most efficient network, and comes close to how each discipline operates, with a set of core journals to which minor, more specialized journals are connected (see Stigler 1994; Stigler et al. 1995; Van Dalen and Henkens 1999). Communication in this model generally moves in one direction-core journals export knowledge to specialized journals and not the other way round (Biehl et al. 2006), as core journals generally reach a large number of readers and practitioners contrarily to specialized journals, which reach more targeted, smaller audiences. Furthermore, because of their size, the price of specialized journals is generally higher than core journals (Klamer and van Dalen 2002). However, it is worth recalling that 'disciplines' are rather large agglomerations (Fry 2004, 2006). As authors from the sociology of science (e.g., Knorr-Cetina 1981; Whitley 1984) have shown, within 'disciplines', there are entities or units which operate with certain rules, such as specialties, groups, invisible colleges, or fields. This means it might be hard to talk about a 'culture' or a 'network model' for a discipline. Notwithstanding, different network structures might emerge depending on the purpose, age, tradition, or boundary conditions under which scientific fields operate. ${ }^{4}$ As Börner and Scharnhorst (2009, p. 169) argue "[s]cience can be

\footnotetext{
4 The authors acknowledge and thank one of the referees for this remark.
} 


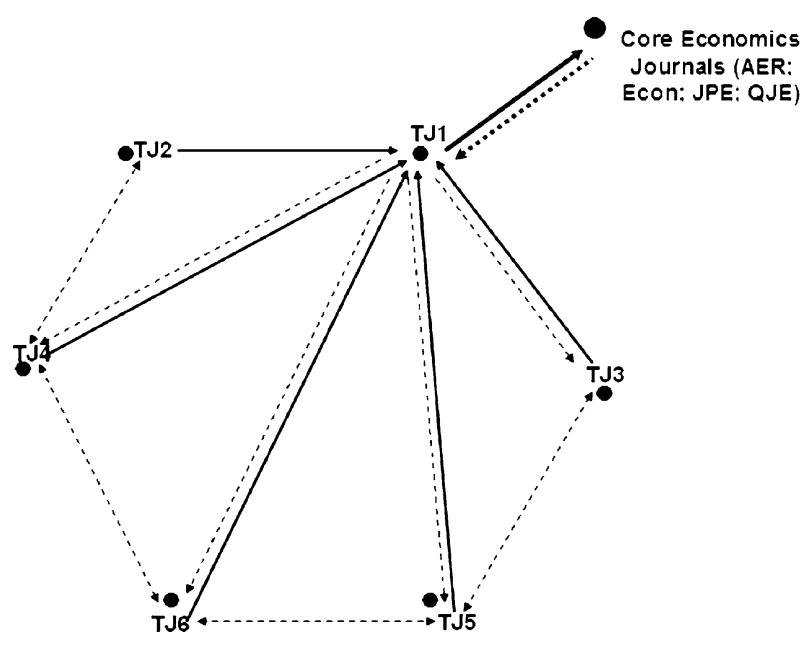

Fig. 2 Relatively autonomous, organized and settled field of research. Note: the direction and thickness of the arrows reflect, respectively, the direction of citation and the relative frequency of citations between 'top journals' (TJ). AER American economic journal, Econ econometrica, JPE journal of political economy, $Q J E$ quarterly economic journal

seen as an evolving system of different basic units of science that are tightly linked and dynamically coupled. Networks are just one product, one trace, or one representation of the collective, self-organized emerging structures in science. But they allow the linking of structural properties to dynamic processes."

Adapting Klamer and van Dalen's (2002) descriptive models of science to the context of scholarly communication within specific sub-disciplines or fields based on journals citation, we propose a modified version of the 'network clusters' (c) - Technology leader sets the standard. Our aim is to understand the cognitive structures, in particular, the degree of autonomy and scientific organization of given fields of research, namely Finance, Management and Marketing. ${ }^{5}$ Each node is now a top-ranked journal (TJ) in the particular area. The direction and thickness (bold versus dashed lines) of the arrows reflect, respectively, the direction of citation and the relative frequency of citations. We thus share with Klamer and van Dalen (2002) that journals citations, and thus the cognitive structure of a given field, partake, at least in part, of some kind of network but that relations between journals are asymmetrical, depicting distinct degrees of strength (Biehl et al. 2006) (Figs. 2, 3).

\footnotetext{
5 It is important to mention here some recent important developments on the models of science. Distinctly from our approach, which is essentially descriptive, these recent developments involve efforts to apply network theoretical and predictive models to science. The Guest Editor's introduction to the Special Issue on "Science of Science: Conceptualizations and Models of Science" in the Journal of Informetrics (Börner and Scharnhorst 2009) contains references to interesting and useful predictive network models of science which aim at achieving a theoretically grounded and practically useful 'science of science'. In particular, the computational proposal of Chen et al. (2009) present an explanatory theory of scientific discovery based on an extended theory of structural holes which conceptualizes scientific discoveries as a brokerage process and also unifies knowledge diffusion as an integral part of a collective information foraging process. In an analogous way, Lambiotte and Panzarasa (2009) argue that scientists at the boundaries of established, wellconnected communities can be crucial for the spreading of new ideas. These latter authors further discuss advantages and disadvantages of close scientific communities and sparsely connected ones concerning information diffusion.
} 


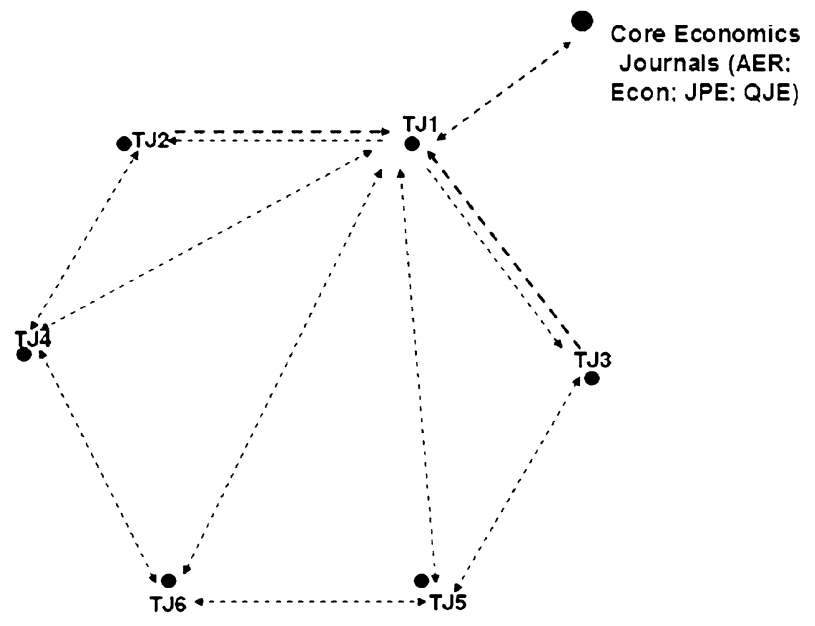

Fig. 3 Relatively non-autonomous, hybrid, and recent field of research. Note: the direction and thickness of the arrows reflect, respectively, the direction of citation and the relative frequency of citations between 'top journals' (TJ). AER American economic journal, Econ econometrica, JPE journal of political economy, $Q J E$ quarterly economic journal

We postulate that in the case of a 'Relatively autonomous, organized and settled field of research', a narrow set of top journals in a given field (e.g., Finance, Management, or Marketing) do cite each other but the most important one (the top of the top, TJ1) is cited to a greater extent (bold arrows). ${ }^{6}$ The latter, in turn, tends to cite, to a reasonable extent, top Economics journals (namely the four 'blue ribbon' journals (Dusansky and Vernon 1998): American Economic Journal, Econometrica, Journal of Political Economy, and Quarterly Economic Journal), which can be considered 'the fundamentals'. In contrast, 'Relatively non-autonomous, hybrid, and recent field of research' displays a more diffuse pattern. Among top journals the reciprocal citations are rather weak, and taking together they account for a relatively small percentage of total citations; there is no well-defined body of 'fundamental theoretical knowledge base', that is, the citation of a given area's top journal or of top Economics journals is negligible.

Following this line of reasoning, we aim to assess which network patterns emerge in the case of Finance, Management and Marketing. The following section details the procedures undertaken to achieve this.

\section{Methodology and results}

The data we used was obtained from the ISI Web of Knowledge database (portal.isiknowledge.com). ISI collects bibliographic information on thousands of journals among which 102 are classified as Management, Marketing and Finance. Its access is limited to subscribers.

\footnotetext{
6 Thus, for assessing 'autonomy', as we empirically exemplify in Sect. 3, we look into the 'relative closure of the network of journals against other journals' (we acknowledge one of the referees for this expression). That is, in a 'relatively autonomous' field of research the percentage of total citations corresponding to a small core of the area's journals is rather high in an excess of 40\% (Waller 2006).
} 
Table 1 ISI web of knowledge 2005 most-cited journals in the area of finance, management and marketing

\begin{tabular}{lllll}
\hline $\begin{array}{l}\text { ISI } \\
\text { ranking }\end{array}$ & $\begin{array}{l}\text { Abbreviated } \\
\text { journal title }\end{array}$ & ISSN & $\begin{array}{l}\text { 2005 Total } \\
\text { citations }\end{array}$ & $\begin{array}{l}\text { Impact } \\
\text { factor }\end{array}$ \\
\hline 1 & J Financ & $0022-1082$ & 8235 & 2.549 \\
2 & Acad Manage J & $0001-4273$ & 6944 & 2.200 \\
3 & Acad Manage Rev & $0363-7425$ & 6387 & 4.254 \\
4 & Strategic Manage J & $0143-2095$ & 6137 & 1.897 \\
5 & Admin Sci Quart & $0001-8392$ & 5906 & 2.719 \\
6 & J Financ Econ & $0304-405 X$ & 5404 & 2.385 \\
7 & J Marketing & $0022-2429$ & 5307 & 4.132 \\
8 & J Marketing Res & $0022-2437$ & 4495 & 2.611 \\
9 & Harvard Bus Rev & $0017-8012$ & 4475 & 1.404 \\
10 & J Consum Res & $0093-5301$ & 4356 & 2.161 \\
11 & Organ Sci & $1047-7039$ & 3142 & 1.989 \\
12 & J Monetary Econ & $0304-3932$ & 2670 & 1.661 \\
13 & J Manage & $0149-2063$ & 2562 & 1.535 \\
14 & Rev Financ Stud & $0893-9454$ & 1984 & 1.893 \\
15 & J Int Bus Stud & $0047-2506$ & 1788 & 1.250 \\
\hline
\end{tabular}

Starting with a list of ISI top-cited journals, we classified them into groups by observing who cites whom.

To start our procedure, we selected the most-cited journal from the ISI Web of Knowledge in the area of Finance, Management and Marketing (see in Table 1 the top 15 journals). This top journal (TJ), i.e., the Journal of Finance (JF), was cited 8235 times in ISI-indexed documents published during $2005 .^{7}$

We used the ISI Total Citations purely as a start condition since it has several limitations (Wouters 1999; Moed 2005). Primarily, it is computed without weighting the relative quality of the media where the citation occurs (it does not even distinguish the document type, i.e., if citations occur in journal articles or conference proceedings papers) and it is not field-specific normalized (differences arise due to dissimilarities in the field-specific proportion of journals/conferences indexed works). The ISI Impact Factor is an even poorer ranking indicator because, in addition to the limitations of "Total Citations", it uses an excessively narrow "citation window" (1-2 years) and the used denominator (the number of 'citable' documents) is frequently computed with error (there is not a consistent classification of articles as 'citable').

The second step involved listing all the articles from the Journal of Finance (JF) and downloading their references, which constitute a starting point for a path that is free to run away from the ISI Web of Knowledge list of journals classified in the area of Finance, Management and Marketing. Based on these references, we constructed a journal ranking

\footnotetext{
7 To evaluate the consequences of having a different initial ranking criterion, we experimented with the use of the Impact Factor and, although the initial journal was different (the Academy of Management Review), the final results were the same (although the first identified group was that of Table 3 ). We also evaluated the consequences of using a different period of analysis (2001-2005) with the same results (reinforcing that journals' ranking is statistically stationary-cf. Vieira 2004).
} 
Table 2 Most-cited journals (starting with Journal of Finance) in the scientific field of finance, 2005

\begin{tabular}{llllllll}
\hline Originlcited & JF $(\%)$ & JFE $(\%)$ & RFS $(\%)$ & J BUS $(\%)$ & JFQA $(\%)$ & Ec core* $(\%)$ & Total $(\%)$ \\
\hline J Finance & 21.5 & 12.0 & 4.3 & 2.1 & 1.2 & 12.5 & 53.5 \\
J Financial Econ & 20.0 & 14.2 & 4.2 & 2.3 & 1.7 & 10.6 & 52.8 \\
Rev Financial Stud & 21.2 & 9.4 & 7.0 & 1.6 & 1.3 & 11.9 & 52.4 \\
J Business & 18.8 & 10.4 & 4.4 & 3.1 & 1.5 & 10.8 & 49.0 \\
J Finance Quant Anal & 23.9 & 16.6 & 5.4 & 2.4 & 3.1 & 6.9 & 58.4 \\
Average & 21.0 & 12.1 & 4.5 & 2.1 & 1.4 & 10.1 & 51.2 \\
\hline
\end{tabular}

* Econ Core-American Economic Review AER, Econometrica Econ, Journal of Political Economy JPE, and Quarterly Journal of Economics QJE

by counting the journals mentioned (see Table 2, the "J Finance" line) where, unintentionally, JF came up as the top journal (self-citations) and the Journal of Financial Economics (JFE) ranked second.

It is important to highlight that this computed ranking is based on citations from the Journal of Finance and is not dependent on the ISI Total Citations start condition. If we have taken instead all 102 journals that ISI classifies as Management, Marketing and Finance, downloading all articles of these journals and performing a direct citation analysis of the whole matrix, we would be, a priori, constrained to the ISI classification procedure, which, as explained earlier we wanted to avoid.

Then, we repeated the second step procedure by listing JFE articles, downloading their references and re-computing the ranking on Table 2 (adding the "J Finance" line to the "J Fin Econ" line) and continued by downloading data from the publication now ranked third (the Review of Financial Studies, RES).

The four 'core' or 'blue ribbon' economics journals (Dusansky and Vernon 1998) American Economic Review (AER); Econometrica (Econ); Journal of Political Economy (JPE), and Quarterly Journal of Economics (QJE) — were, in a first stage, excluded. Then, we devised a way to incorporate these 'economics' journals, which form quite a distinct group from those analyzed directly in this paper (Finance, Management and Marketing).

The second step procedure was repeated for the journals ranked next on Table 2 (Journal of Business, JBus, and, finally, Journal of Finance and Quantitative Analyses, JFQA). Table 2 summarizes the results.

The procedure was terminated when the journals identified in this manner ranked low on the 2005 ISI Total Citations ranking summarized in Table 1. Figure 4 describes in a schematic way this two step procedure undertook for Finance, Management and Marketing fields of research.

As the initial journal is the Journal of Finance, and all the journals listed are financerelated, it seems obvious to locate the Table 2 group of journals in the scientific field of Finance.

As can be seen in Table 2, on average, $43 \%$ of the total citations in the area of Finance go to works published in a narrow set of journals. This fact indicates that Finance is an autonomous, organized and settled field of research (cf. Fig. 2). In this scientific field, it is clearly "assumed" by all five top journals that JF is the 'top of the top', JFE ranks second, and RFS is third. Furthermore, all five journals are "finance general" and not sub-field specific (as they have a limited percentage of "self-citations"). 


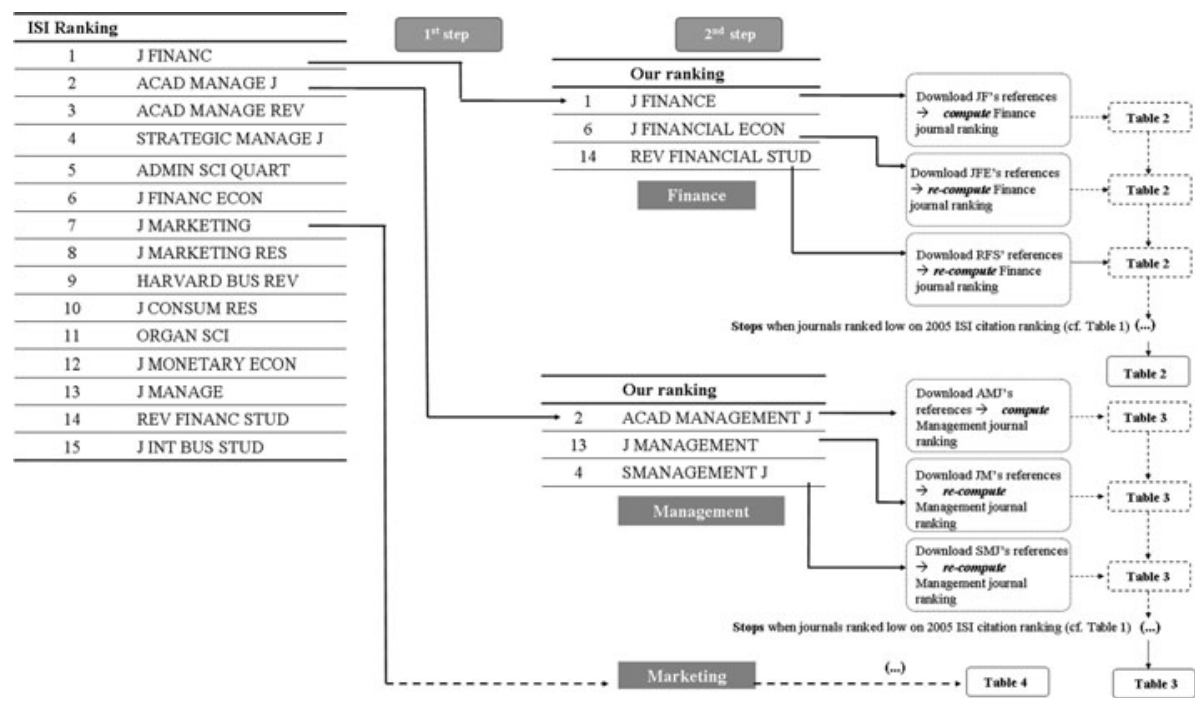

Fig. 4 Short description of the two-step recursive algorithm

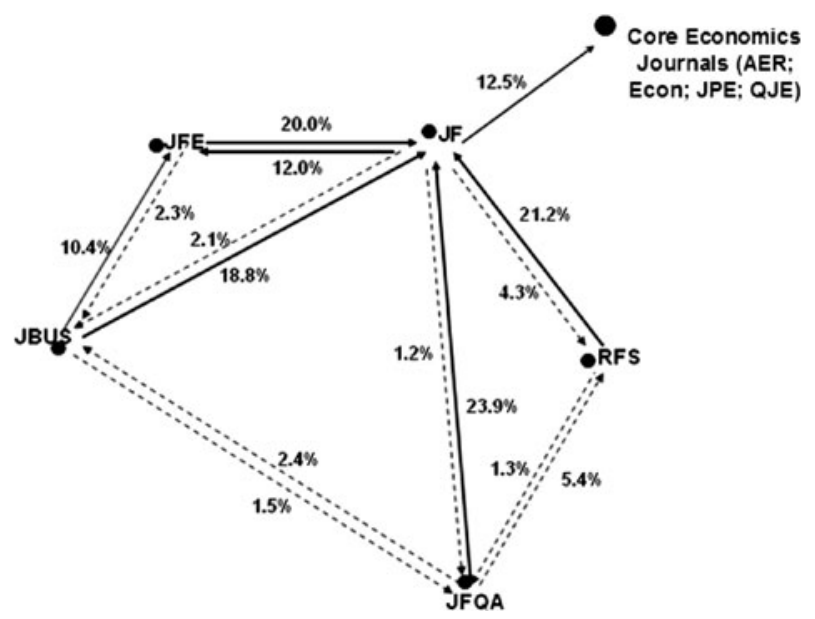

Fig. 5 Finance as a 'Relatively autonomous, organized and settled field of research' Note: We considered, following Biehl et al. (2006), that a tie (link between two TJ) representing less than $10 \%$ of a journal's citations as weak (dashed line), whereas a tie involving $10 \%$ and over of a journal's citations presents a strong tie (bold line)

What is particularly interesting is the Finance scientific field's strong linkage to Core Economics Journals. On average, ten per cent of these citations in the top Finance journals refer to the American Economic Review, Econometrica, Journal of Political Economy, and Quarterly Journal of Economics (Fig. 5).

To identify the second scientific field, we reset the top journal identification procedure by eliminating those journals allocated to the Finance group from Table 1 and selecting one of the remaining top ISI-ranked journals (i.e., the Academy Management Journal, AMJ). It is quite interesting to note that Finance is unrelated with the second ISI-ranked 
Table 3 Most-cited journals (starting with the Academy Management Journal) in the field of management, 2005

\begin{tabular}{llrlrllll}
\hline Originlcited & $\begin{array}{l}\text { AMJ } \\
(\%)\end{array}$ & \multicolumn{1}{c}{$\begin{array}{l}\text { ASQ } \\
(\%)\end{array}$} & $\begin{array}{l}\text { AMR } \\
(\%)\end{array}$ & $\begin{array}{l}\text { SMJ } \\
(\%)\end{array}$ & $\begin{array}{l}\text { J M } \\
(\%)\end{array}$ & OS $(\%)$ & $\begin{array}{l}\text { Ec Core } \\
(\%)\end{array}$ & $\begin{array}{l}\text { Total } \\
(\%)\end{array}$ \\
\hline Acad Management J & 9.50 & 7.94 & 5.28 & 5.66 & 2.38 & 2.34 & 1.59 & 34.68 \\
Admin Science Quart & 6.04 & 10.54 & 4.71 & 1.43 & 1.02 & 3.28 & 1.64 & 28.66 \\
Acad Management Rev & 4.48 & 4.80 & 4.80 & 3.44 & 1.69 & 1.62 & 1.75 & 22.58 \\
Strategic Management J & 6.10 & 3.18 & 2.93 & 12.92 & 2.26 & 2.98 & 2.73 & 33.10 \\
J Management & 7.16 & 4.04 & 4.77 & 5.46 & 4.66 & 2.00 & 0.77 & 28.86 \\
Organisation Science & 4.43 & 6.53 & 3.23 & 2.21 & 1.91 & 4.50 & 1.43 & 24.24 \\
Average & 5.64 & 5.30 & 4.18 & 3.64 & 2.40 & 2.95 & 1.65 & 28.69 \\
\hline
\end{tabular}

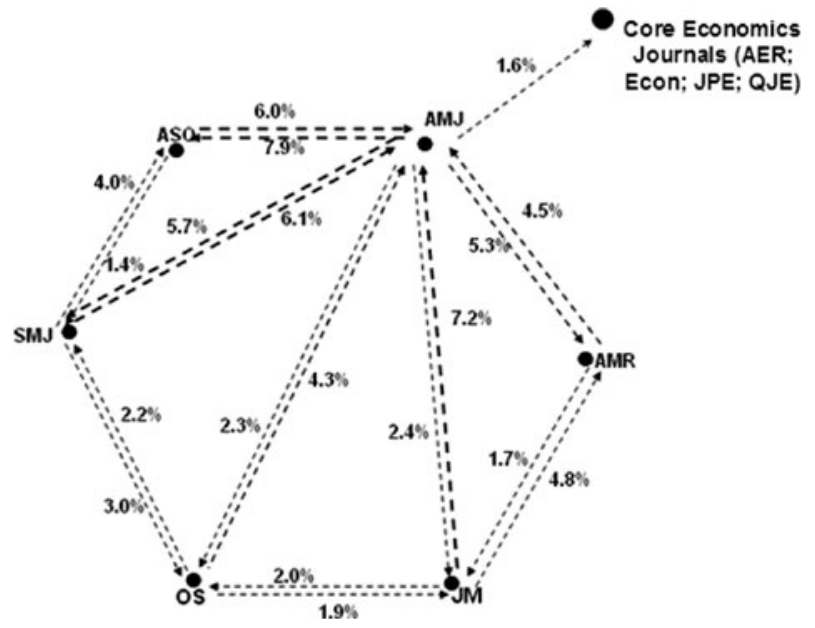

Fig. 6 Management as a 'Relatively non-autonomous, hybrid, and recent field of research'. Note: We considered, following Biehl et al. (2006), that a tie (link between two TJ) representing less than $10 \%$ of a journal's citations as weak (dashed line), whereas a tie involving $10 \%$ and over of a journal's citations presents a strong tie (bold line)

journal (i.e., AMJ): from a total of 14,334 works cited in articles from those five Finance journals in 2005, only six where published in the AMJ (see also Table 7).

The results for the new group of journals, the Management scientific field, are summarized in Table 3. It should be noted that Management journals do not cite Finance journals either (see Table 7). Moreover, citations are much more dispersed than in the Finance-related scientific field-in Management, on average, less than $30 \%$ of the total citations in top-ranked journals derive from this group of journals, the top of the top is not so clear-cut, and self-citations are much more important (in five of the six journals, they are the major source of the works cited).

Given these results, from a theoretical point of view, Management appears here as a relatively non-autonomous, hybrid, and recent field of research (see Fig. 6).

Finally, to identify the third scientific field, Marketing, the procedure is once more reset with the last top journal (the seventh ISI-ranked journal-the Journal of Marketing). Table 4 
Table 4 Most-cited journals (starting with Journal of Marketing) in the area of marketing, 2005

\begin{tabular}{lclcccc}
\hline Originlcited & MS (\%) & JMR $(\%)$ & JM $(\%)$ & JCR $(\%)$ & Ec Core $(\%)$ & Total (\%) \\
\hline Market Sci & 18.37 & 7.48 & 2.64 & 0.72 & 4.98 & 15.82 \\
J Marketing Res & 10.25 & 8.49 & 8.49 & 3.81 & 0.60 & 21.38 \\
J Marketing & 4.28 & 2.92 & 16.55 & 1.66 & 0.33 & 21.45 \\
J Consum Res & 2.63 & 7.17 & 4.65 & 22.27 & 4.39 & 38.48 \\
Average & 5.72 & 5.86 & 5.26 & 2.06 & 2.58 & 19.55 \\
\hline
\end{tabular}

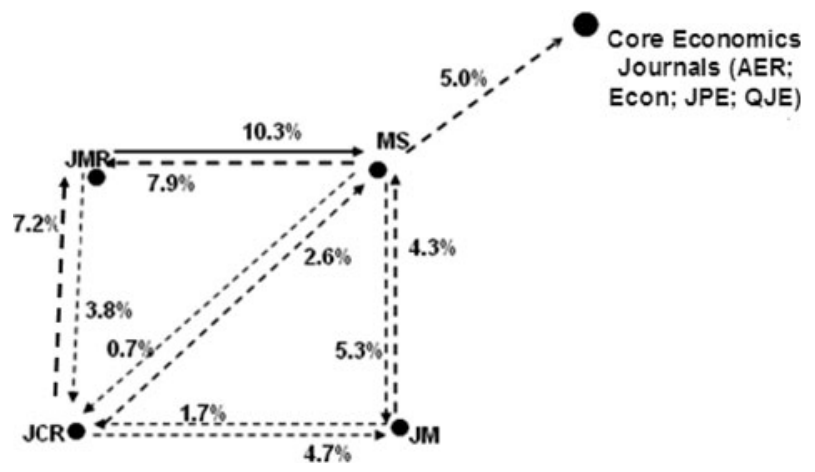

Fig. 7 Marketing as a 'Relatively non-autonomous, hybrid, and recent field of research'. Note: we considered, following Biehl et al. (2006), that a tie (link between two TJ) representing less than 10\% of a journal's citations as weak (dashed line), whereas a tie involving $10 \%$ and over of a journal's citations presents a strong tie (bold line)

summarizes the results. Data show similarities to the case of Management, although here it is more apparent that there is no clear 'leader', and that self citations are very important, which indicates that there are no "general marketing" journals. Moreover, on average, only $17 \%$ of citations come from these 'top' Marketing journals (it is a hybrid field of research).

Similarly to Management, but presenting an even more dispersed and hybrid pattern, Marketing displays a network which reflects a non-autonomous, hybrid, and recent field of research (see Fig. 7).

In the third step, based on the citation data, sub-discipline rankings were constructed using the recursive methodology of Liebowitz and Palmer (1984), which computes the average relative impact of each paper published. This methodology, relying extensively on Moore's (1972) seminal work, has developed into the standard for the quality evaluation of journals (e.g., Laband and Piette 1994; Kalaitzidakis et al. 2003).

Given that $I_{m}$ is the average impact of journal $m$ and $K_{m, n}$ the percentage of citations from journal $m$ articles in journal $n$ (where $N$ is the number of journals used in the computation), then the average journal impact, $I_{m}$, is computed by the next expression where parameter $\xi$ is a scale factor that normalizes the top-ranking journal's impact to 100 .

$$
I_{m}=\frac{\sum_{n=1}^{N} K_{m, n} \cdot I_{n}}{\xi}
$$

Applying this procedure to our data (summarized on Tables 2, 3, and 4), a ranking of the journals in the three groups was obtained (see Table 5), where it becomes apparent that 
Table 5 Relative impact of the most cited journals (finance, management and marketing)

\begin{tabular}{|c|c|c|c|c|c|}
\hline \multicolumn{2}{|l|}{ Finance } & \multicolumn{2}{|l|}{ Management } & \multicolumn{2}{|l|}{ Marketing } \\
\hline Journal title & Impact & Journal title & Impact & Journal title & Impact \\
\hline$J$ Financ & 100.00 & Acad Manage $\mathbf{J}$ & 100.00 & Market Sci & 100.00 \\
\hline $\mathrm{J}$ Financ Econ & 69.91 & Admin Sci Quart & 96.47 & J Market Res & 84.05 \\
\hline Rev Financ Stud & 32.04 & Acad Manage Rev & 80.70 & J Marketing & 83.55 \\
\hline J Bus & 16.66 & Strategic Manage $\mathrm{J}$ & 70.42 & J Consum Res & 34.36 \\
\hline J Financ Quant Anal & 11.59 & $\mathrm{~J}$ Manage & 63.91 & & \\
\hline & & Organ Sci & 45.71 & & \\
\hline
\end{tabular}

there is a clear top of the top Finance journal but this is not the case of Management or Marketing.

Note that, due to the independence of the computation (among other causes, the use of a different scale factor $\xi$ ), the journals' impact is not comparable amongst groups (i.e., it is not an absolute measure of the journals' quality). Looking at expression (1), self-citations have an important role in relative impact, at least theoretically. Nonetheless, as all journals have a relatively high proportion of self-citations, their exclusion has no impact on Table 5 computed a relative impact.

Using the Table 5 impact as a weighting factor, we were able to quantify the degree of independence among the scientific areas that these three groups of journals represent and their dependence on other scientific areas, namely Economics, Psychology and Sociology. First, we computed an extended sub-field area ranked with 25 journals, where the weight factors are the impact indexes that we computed and present in Table 5 (see Table 6).

Table 6 shows that the Finance scientific field has a very important connection with Economics and a minor one with Accounting, whereas Management is more disperse, having important connections with Psychology and Sociology and minor connections with Marketing and Economics. In the case of Marketing, a more hybrid and disperse picture arises, which corroborates the network analysis performed earlier.

We quantified the degree of (in)dependence among the scientific fields by adding information for each scientific field to Table 6 and computing their relative importance, to a total sum of $100 \%$. We obtained a summary of the degree of (in)dependence among the scientific fields of Finance, Management, and Marketing that we organized on the Table 7 matrix.

\section{Conclusions}

Based on Klamer and Van Dalen's (2002) theoretical framework of science as 'network clusters' we propose a modified version of the 'Technology leader sets the standard network', in order to map the degree of autonomy and scientific organization of Finance, Management and Marketing (rather underexplored domains in scientometric studies).

Resorting to the recursive methodology of Liebowitz and Palmer (1984), we put forward a hybrid method, which combines the ISI classification of journals and citations. Some interesting results were obtained which are here summarized and discussed in light of the existing related literature, namely that of sociology of science. 


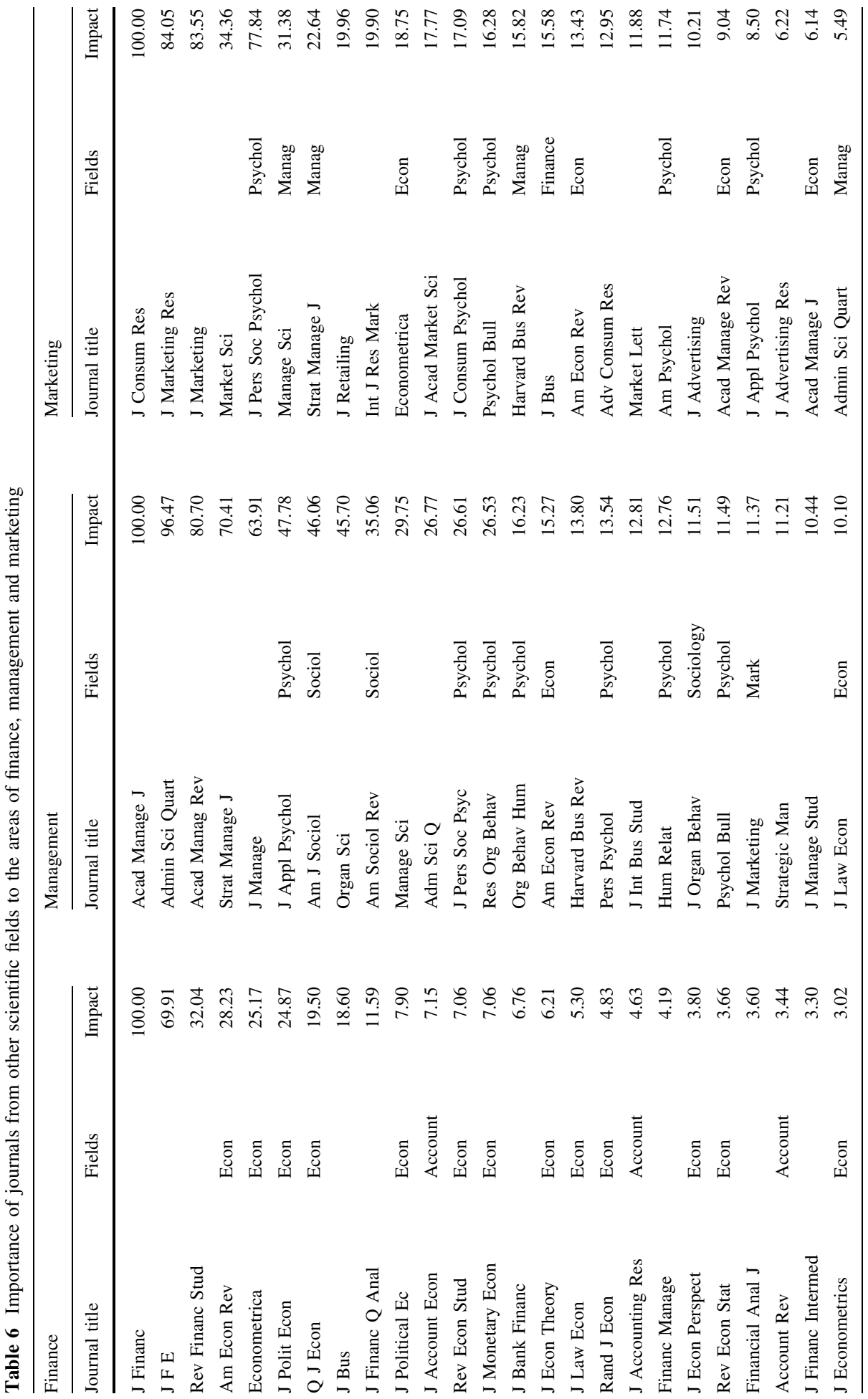


Table 7 (In)dependence of finance, management and marketing (relative importance of other scientific fields)

\begin{tabular}{lcllllrl}
\hline Fieldslcontributes & $\begin{array}{l}\text { Finance } \\
(\%)\end{array}$ & $\begin{array}{l}\text { Management } \\
(\%)\end{array}$ & $\begin{array}{l}\text { Marketing } \\
(\%)\end{array}$ & $\begin{array}{l}\text { Econ. } \\
(\%)\end{array}$ & \multicolumn{1}{l}{$\begin{array}{l}\text { Psychol. } \\
(\%)\end{array}$} & \multicolumn{1}{l}{$\begin{array}{l}\text { Sociol. } \\
(\%)\end{array}$} & \multicolumn{1}{l}{$\begin{array}{l}\text { Accounting } \\
(\%)\end{array}$} \\
\hline Finance & 60.70 & 0.00 & 0.00 & 35.60 & 0.00 & 0.00 & 3.70 \\
Management & 0.00 & 61.00 & 6.74 & 3.00 & 18.31 & 10.95 & 0.00 \\
Marketing & 2.32 & 11.23 & 59.78 & 7.06 & 19.60 & 0.00 & 0.00 \\
\hline
\end{tabular}

We demonstrated that Finance is an autonomous, organized and settled field of research, as a substantial share of the total citations in this area goes to works published in a narrow set of (Finance-related) journals and there is a clear 'top of the top' journal, Journal of Finance. The Finance scientific field shows strong linkages to core Economics journals, which is in line with the results obtained by Biehl et al. (2006). According to these authors, Finance relies heavily on Economics principles and methods and many Finance academics are also trained economists, which justifies that Finance keeps drawing upon the Economics literature to integrate new thoughts into the respective mainstream literature. According to our data, on average, ten per cent of these citations in top Finance journals refer to the four 'blue ribbon' economics journals (American Economic Review, Econometrica, Journal of Political Economy, and Quarterly Journal of Economics), which might be considered a strong tie.

Furthermore, in the case of Management journals, they do not cite Finance journals, revealing that these two scientific fields are rather insulated from one another. Citations in the Management field are much more dispersed than in the Finance scientific field and the 'top of the top' journal is not so clear-cut. Moreover, self-citations are much more important, which reveals a certain degree of 'inwardness' of the community supporting the specialty (Leydesdorff 2007). We then conclude that Management appears here as a relatively non-autonomous, hybrid, and recent field of research.

Finally, results for Marketing show similarities to the case of Management, although they are even more apparent, in that there is no clear 'leader' and self citations are much more prominent, reflecting what Biehl et al. (2006) call a 'tight research cluster'. The producers of research also become the main consumers of that research, which results in minimal contributions to outside the cluster (inwardness in Leydesdorff's wording). Thus, similarly to Management, but presenting an even more dispersed and hybrid pattern, Marketing displays a network which reflects a non-autonomous, hybrid, and recent field of research. Despite its 'solitude' and 'insulation', these two research fields have some noticeable dependency on Psychology, in the case of Marketing, and Psychology and Sociology, in the case of Management.

Based on our results and some recent studies on citations analysis focused on the three fields considered here (e.g., Biehl et al. 2006; Waller 2006), we can pertinently frame the evidence within Whitley's (1984) theory, which considers both epistemological and social structures within 'disciplines', explaining cultural difference across these 'disciplines' based on two dimensions of scholarly practices, 'mutual dependency' and 'task uncertainty'. 'Mutual dependency' relates specifically to the extent to which a field is dependent on knowledge produced in other fields in order to make a significant contribution to science; it also includes the degree of interdependence between scientists and groups in a field, and the extent to which a field adopts evaluation criteria and standards from other fields for the assessment of work produced outside its intellectual boundary, rather than 
developing its own criteria for evaluating externally produced knowledge (Fry 2004). 'Task uncertainty' concerns the unpredictability of task outcomes-because the sciences are committed at an institutional level to produce novel results, research activities are 'uncertain compared to other work activities' in that 'outcomes are not repetitious and highly predictable' (Whitley 1984).

Whitley's taxonomy constitutes an effective tool for explaining differences in patterns of behaviour and adoption of networked resources across specialist fields (Fry and Talja 2005). Accordingly, in fields with a high degree of mutual dependence and a low degree of task uncertainty all conditions exist where the research object, research techniques, and significance criteria are highly coordinated. The maintenance of coordination and conformity to the communicative norms will be enabled because these fields are, by and large, single paradigm fields. This means that they have a stable research object and relatively uncontested field boundaries. As such, scatter of literature is limited and material is focused within the organizational boundaries and core journals of the field. This seems to be the case of the Finance field analyzed in this paper.

In those fields where the degree of mutual dependence is low, but the degree of task uncertainty is high, the research object, research techniques, and significance criteria are only minimally coordinated. Boundary skirmishes may be common and research topics, goals, and priorities may be pluralistic and individualistic (Fry and Talja 2005). Our results on the hybridism of the fields, that is the diversity and importance of journals from scientific fields outside the area in analysis (Finance, Management or Marketing), confirm that both Management and Marketing share characteristics of a low degree of mutual dependence and a high degree of task uncertainty.

The above discussion, although challenging and quite interesting from the scientific point of view, requires a more in-depth analysis on the sociology of these research fields. As Fry (2004) correctly asserts, "Whitley's theory does not explain the whole story"; other influential cultural factors that fall outside of the scope of his taxonomy, such as levels of interpersonal recognition amongst community members, size of field, and institutional frameworks for the organization of knowledge-producing communities (with their potential effect on factors such as the formation of critical mass, recognition and reward, and quality control systems), might came into play.

Acknowledgements The authors are deeply indebted for helpful comments and suggestions of two anonymous referees. The usual caveat applies.

\section{References}

Alexander, J., Jr., \& Mabry, R. (1994). Relative significance of journals, authors, and articles cited in financial research. The Journal of Finance, XLIX(2), 697-712.

Avkiran, N. K. (1997). Scientific collaboration in Finance does not lead to better quality research. Scientometrics, 39(2), 173-184.

Becher, T. (1989). Academic tribes and territories: Intellectual enquiry and the culture of disciplines. Buckingham: SRHE \& Open University Press.

Bensman, S. J. (2001). Bradford's Law and fuzzy sets: Statistical implications for library analyses. IFLA Journal, 27, 238-246.

Bhattacharya, S., \& Basu, P. K. (1998). Mapping a research area at the micro level using co-word analysis. Scientiometrics, 43, 359-372.

Biehl, M., Kim, H., \& Wade, M. (2006). Relationships among the academic business disciplines: A multimethod citation analysis. Omega, 34, 359-371.

Borgman, C. (2007). Scholarship in the digital age information infrastructure, and the internet. Cambridge: MIT Press. 
Borgman, C., \& Furner, J. (2002). Scholarly communication and bibliometrics. Annual Review of Information Science and Technology, 36, 3-72.

Börner, K., Chen, C., \& Boyack, K. (2003). Visualizing knowledge domains. Annual Review of Information Science and Technology, 37, 179-255.

Börner, K., \& Scharnhorst, A. (2009). Guest Editor's introduction to the special issue on "science of science: Conceptualizations and models of science". Journal of Informetrics, 3, 161-172.

Braam, R. R., Moed, H. F., \& van Raan, A. F. (1991). Mapping of science by combined co-citation and word analysis, I: Structural aspects. Journal of the American Society for Information Science, 42, 233-251.

Bush, W. C., Hamelman, P. W., \& Staaf, P. J. (1974). A quality index for economic journals. Review of Economics and Statistics, 56, 123-125.

Callon, M., Courtial, J. P., Turner, W. A., \& Bauin, S. (1983). From translations to problematic networks: An introduction to co-word analysis. Social Science Information, 22, 191-235.

Chen, C., Chen, Y., Horowitz, M., Hou, H., Liu, Z., \& Pellegrino, D. (2009). Towards an explanatory and computational theory of scientific discovery. Journal of Informetrics, 3(3), 191-209.

Clements, K. W., \& Wang, P. (2003). Who cites what? Economic Record, 79(245), 229-244.

de Solla Price, D. (1965). Networks of scientific papers. Science, 149(3683), 510-515.

de Wilde, R. (1992). Discipline en legende. De identiteit van de sociologie in Duitsland en de Verenigde Staten 1870-1930, Van Gennep, Amsterdam.

Dusansky, R., \& Vernon, C. (1998). Rankings of U. S. economics departments. Journal of Economic Perspectives, 12(1), 157-170.

Eto, H. (2002). Authorship and citation patterns in management science in comparison with operational research. Scientometrics, 53(3), 337-349.

Franck, G. (1999). Scientific communication-a vanity fair? Science, 286, 53-55.

Frey, B. S., \& Eichenberger, R. (1997). Economists: First semester, high flyers and UFOs. In P. A. G. Van Bergeijk, A. L. Bovenberg, E. E. C. van Damme, \& J. van Sinderen (Eds.), Economic science and practice (pp. 15-48). Cheltenham: Edward Elgar.

Fronczak, P., Fronczak, A., \& Holyst, J. A. (2006). Self-organized criticality and co-evolution of network structure and dynamics. Physical Review E, 73, 046117.

Fry, J. (2004). The cultural shaping of ICTs within academic fields: Corpus-based linguistics as a case study. Literary and Linguistic Computing, 19(3), 303-319.

Fry, J. (2006). Studying the scholarly web: How disciplinary culture shapes online representations. Cybermetrics: International Journal of Scientometrics, Informetrics and Bibliometrics, 10(1). Available at: http://www.cindoc.csic.es/cybermetrics/vol10iss1.html.

Fry, J., \& Talja, S. (2005). The cultural shaping of scholarly communication: Explaining e-journal use within and across academic fields. Proceedings of the American Society for Information Science and Technology, 41(1), 20-30.

García-Aracil, A., Gracia, A. G., \& Pérez-Marín, M. (2006). Analysis of the evaluation process of the research performance: An empirical case. Scientometrics, 67(2), 213-230.

Garfield, E. (1986). Essays of an information Scientist: 1986. In Towards Scientography. Preface (Vol. 9, pp. xi-xii).

Garfield, E. (2009). From the science of science to Scientometrics visualizing the history of science with HistCite software. Journal of Informetrics, 3, 173-179.

Gerrity, D. M., \& Mckenzie, R. B. (1978). The ranking of southern economic departments: New criterion and further evidence. Southern Economic Journal, 45, 608-614.

Hamelman, P. W., \& Mazze, E. M. (1974). Citations patterns in finance journals. Journal of Finance, 29, 1295-1301.

Kalaitzidakis, P., Mamuneas, T. P., \& Stengos, T. (2003). Rankings of academic journals and institutions in economics. Journal of the European Economic Association, 1, 1346-1366.

Klamer, A., \& van Dalen, H. (2002). Attention and the art of scientific publishing. Journal of Economic Methodology, 9(3), 289-315.

Knorr-Cetina, K. D. (1981). The manufacture of knowledge: An essay on the constructivist and contextual nature of science. Oxford: Pergamon Press.

Laband, D., \& Piette, M. (1994). The relative impact of economic journals. Journal of Economic Literature, $32,640-666$.

Lambiotte, R., \& Panzarasa, P. (2009). Communities, knowledge creation and information diffusion. Journal of Informetrics, 3(3), 180-190.

Lewison, G. (1999). The definition and calibration of biomedical subfields. Scientometrics, 46, 529-537.

Leydesdorff, L. (2002). Indicators of structural change in the dynamics of science: Entropy statistics of the sc journal citation reports. Scientometrics, 53(1), 131-159. 
Leydesdorff, L. (2004a). Clusters and maps of science journals based on bi-connected graphs in the journal citation reports. Journal of Documentation, 60(4), 371-427.

Leydesdorff, L. (2004b). Top-down decomposition of the journal citation report of the social science citation index: Graph- and factor-analytical approaches. Scientometrics, 60(2), 159-180.

Leydesdorff, L. (2007). Visualization of the citation impact environments of scientific journals: An online mapping exercise. Journal of the American Society for Information Science and Technology, 58(1), 25-38.

Leydesdorff, L. (2008). The delineation of nanoscience and nanotechnology in terms of journals and patents: A most recent update. Scientometrics, 76(1), 159-167.

Leydesdorff, L., \& Bensman, S. J. (2006). Citations, powerlaws, and logarithmic transformations. Journal of the American Society for Information Science and Technology, 57(11), 1470-1486.

Leydesdorff, L., \& Cozzens, S. E. (1993). The delineation of specialties in terms of journals using the dynamic journal set of the science citation index. Scientometrics, 26, 133-154.

Leydesdorff, L., \& Zhou, P. (2007). Nanotechnology as a field of science: Its delineation in terms of journals and patents. Scientometrics, 70(3), 693-713.

Liebowitz, S. J., \& Palmer, J. P. (1984). Assessing the relative impacts of economics journals. Journal of Economic Literature, 22, 77-88.

Lozano, S., \& Salmerón, J. (2005). Data envelopment analysis of OR/MS journals. Scientometrics, 64(2), $133-150$.

Mabry, R, H., \& Sharplin, A. D. (1985). The relative importance of journals used in financial research. Journal of Financial Research, 8, 287-296.

Macri, J., \& Sinha, D. (2006). Rankings methodology for international comparisons of institutions and individuals: an application to economics in Australia and New Zealand. Journal of Economic Surveys, 20(01), 111-156.

Moed, H. F. (2005). Citation analysis in research evaluation. Dordrecht, Netherlands: Springer.

Moore, W. J. (1972). The relative quality of economics journals: A suggested rating system. Western Economic Journal, 10, 156-169.

Narin, F., Carpenter, M., \& Berlt, N. C. (1972). Interrelationships of scientific journals. Journal of the American Society for Information Science, 23, 323-331.

Newman, M., Barabási, A.-L., \& Watts, D. J. (2006). The structure and dynamics of networks. Princeton: Princeton University Press.

Noyens, E. C. M., \& Van Raan, A. F. J. (1998). Advanced mapping of science and technology. Scientometrics, 41(1-2), 61-67.

Noyons, E. C. M., Luwel, M., \& Moed, H. F. (1999). Combining mapping and citation analysis for evaluative bibliometric purposes. A bibliometric study on recent development in micro-electronics. Journal of the American Society for Information Science and Technology, 50, 115-131.

Parks, R. (2002). The Faustian grip of academic publishing. Journal of Economic Methodology, 9(3), 317-335.

Polanyi, M. (1962/1969). The republic of science: Its political and economic theory. In Knowing and Being (pp. 49-72). Chicago: University of Chicago Press.

Rigney, D., \& Barnes, D. (1980). Patterns of interdisciplinary citation in the social sciences. Social Science Quarterly, 61(1), 114-127.

Saad, G. (2010). Applying the h-index in exploring bibliometric properties of elite marketing scholars. Scientometrics, 83, 423-433.

Schwechheimer, H., \& Winterhager, M. (2001). Mapping interdisciplinary research fronts in neuroscience: A bibliometric view to retrograde amnesia. Scientometrics, 51, 311-318.

Schwert, G. W. (1993). The Journal of Financial Economics: A retrospective evaluation (1971-1991). Journal of Financial Economics, 33, 369-424.

Small, H. G. A. (1977). Co-citation model of a scientific specialty: A longitudinal study of collagen research. Social Studies of Science, 7, 139-166.

Small, H., \& Sweeney, E. (1985). Clustering the science citation index using co-citations I. A comparison of methods. Scientometrics, 7, 391-409.

Stigler, S. M. (1994). Citation patterns in the journals of statistics and probability. Statistical Science, 9 , 94-108.

Stigler, G. J., Stigler, S. M., \& Friedland, C. (1995). The journals of economics. Journal of Political Economy, 103, 331-359.

Swygart-Hobaugh, A. J. (2004). A citation analysis of the quantitative/qualitative methods debate's reflection in sociology research: Implications for library collection development. Library Collections, Acquisitions and Technical Services, 28(2), 180-195. 
van Dalen, H. P., \& Henkens, K. (1999). How influential are demography journals? Population and Development Review, 25, 229-251.

van Raan, A. F. (2000). On growth, ageing, and fractal differentiation of science. Scientometrics, 47, 347-362.

van Raan, A. F. (2004). Measuring science. Capita Selecta of Current Main Issues. In H. F. Moed, W. Glänzel \& U. Schmoch (Eds.), Handbook of quantitative science and technology research (Chap. 1, pp. 19-50). Dordrecht, Netherlands: Kluwer

Vieira, P. C. C. (2004). Statistical variability of top ranking economics journal impact. Applied Economics Letters, 11, 945-948.

Waller, J. H. (2006). Evaluating scholarly communication at the subdisciplinary level. Collection Management, 30(2), 45-57.

White, H., \& McCain, K. (1998). Visualizing a discipline: An author co-citation analysis of information science, 1972-1995. Journal of the American Society for Information Science, 49(4), 327-355.

Whitley, R. (1984). The intellectual and social organization of the sciences. Oxford: Clarendon Press.

Wouters, P. (1999). The citation culture. Ph.D. Dissertation. Amsterdam: University of Amsterdam.

Zitt, M. (2006). Scientometric indicators: A few challenges. Data mine-clearing, knowledge flows measurements, diversity issues, invited plenary talk. In Proceedings international workshop on webometrics, informetrics and scientometrics \& seventh COLLNET meeting, Nancy (France). http://eprints. rclis.org/archive/00006306/. 